\title{
Understanding Teacher Perceptions of Assistive Technology
}

\author{
by \\ Bronwyn Sarah Lamond
}

A thesis submitted in conformity with the requirements

for the degree of Master of Arts

Department of Applied Psychology and Human Development

University of Toronto

(C) Copyright by Bronwyn Sarah Lamond 2018 


\title{
Understanding Teacher Perceptions of Assistive Technology
}

\author{
Bronwyn Sarah Lamond \\ Master of Arts \\ Department of Applied Psychology and Human Development \\ University of Toronto
}

2018

\begin{abstract}
This research examined grade 6-10 Ontario Certified Teachers' $(n=24)$ perceptions of assistive technology (AT), and the factors correlated with perceived usefulness of AT. A mixed-methods design, which included a survey consisting of open- and closed-ended items elicited information about teachers' AT knowledge and training, their basic computer literacy, their perception of administrative support for access to and implementation of AT, the usefulness of AT, and the factors that encourage or discourage AT use in the classroom. Results of correlational analysis suggested that computer literacy and AT knowledge were significantly positively correlated with perceived usefulness of AT and a thematic analysis further identified that training and student factors may influence AT use. Implications for pre-service and professional development teacher training are discussed given the consistency of teacher-reported need for greater training opportunities for both students and teachers.
\end{abstract}




\section{Acknowledgments}

I would first like to thank my thesis advisor, Dr. Todd Cunningham, whose office was always open whenever I had a question about my research or writing. Without his passionate participation and input, this research could not have been successfully conducted.

I would also like to acknowledge Dr. Esther Geva as the second reader of this thesis, and I am gratefully indebted to her for her very valuable comments.

Finally, I must express my very profound gratitude to my parents, Elaine and Bruce, to my partner, Colton, and to my wonderful friends and family for providing me with unfailing support and continuous encouragement throughout my years of study and through the process of researching and writing this thesis. This accomplishment would not have been possible without them. Thank you. 


\section{Table of Contents}

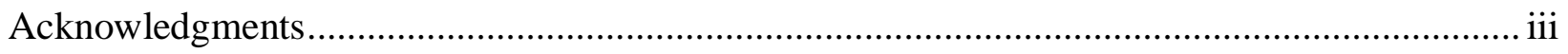

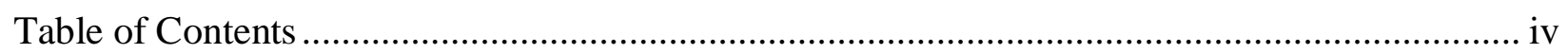

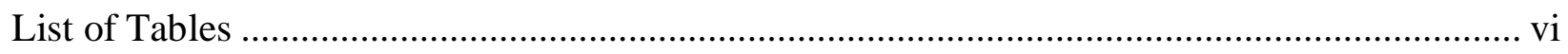

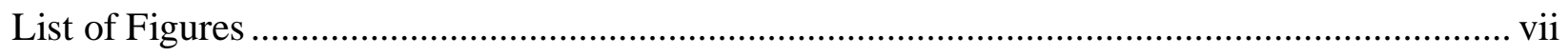

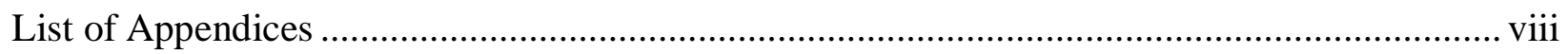

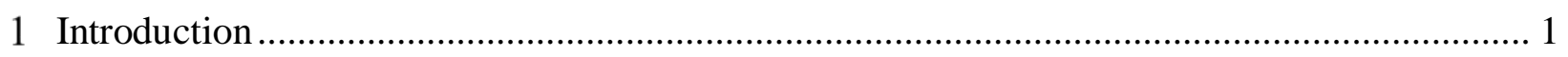

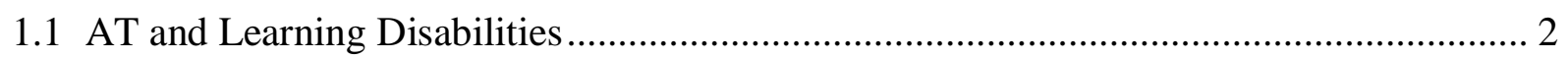

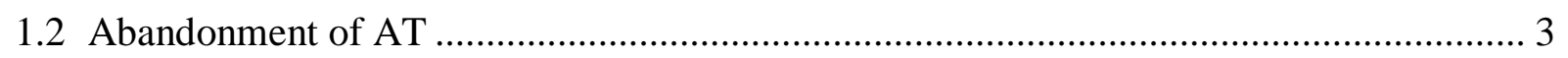

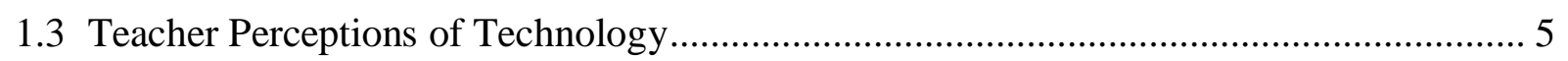

1.3.1 Computer Literacy ……………………………….................................... 5

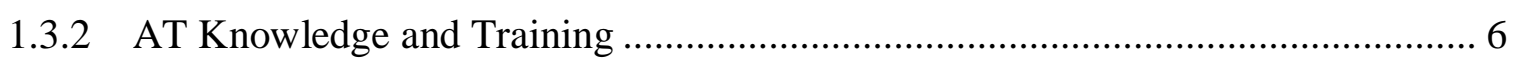

1.3.3 Administrative Support for AT ................................................................... 7

1.3.4 Perception of Usefulness of AT .................................................................... 8

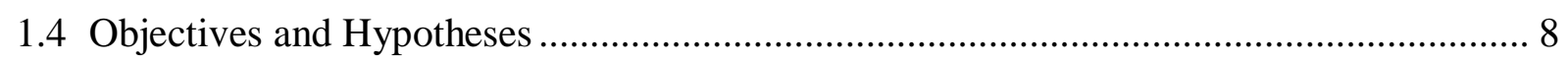

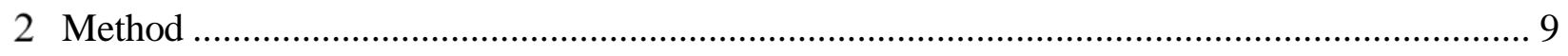

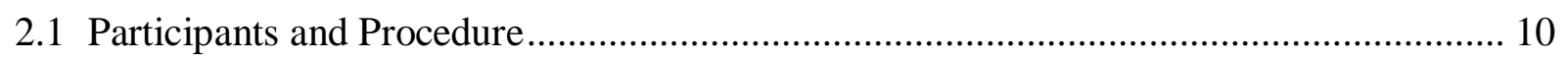

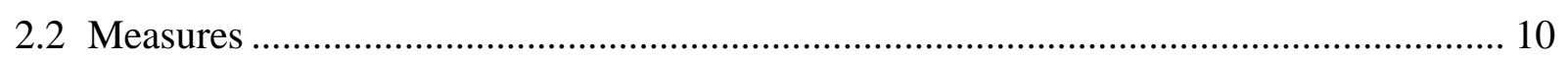

2.2.1 Demographic Information........................................................................... 11

2.2.2 AT Knowledge, Training, and Perception of Support ....................................... 11

2.2.3 Technology Equipment and Computer Literacy .................................................. 11

2.2.4 Perception of Usefulness............................................................................... 11

2.2.5 Factors Influencing the Use of AT ............................................................... 12

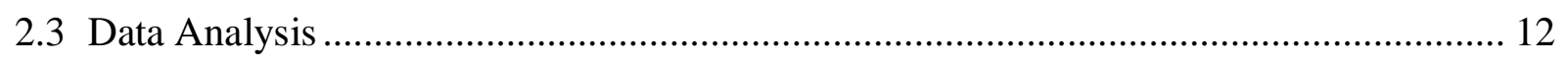

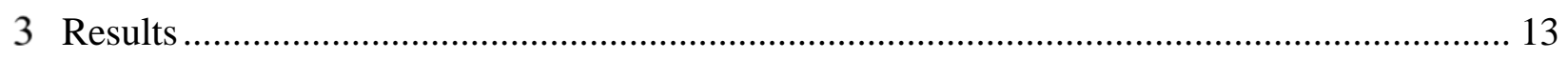

3.1 Characteristics of Study Participants and Their Students .............................................. 13 
3.2 Variables Related to AT Perceived Usefulness ............................................................. 13

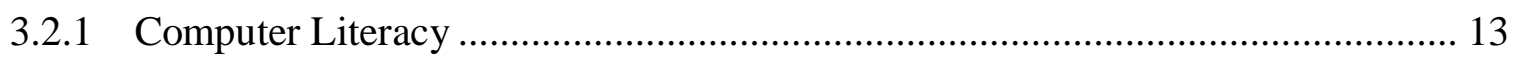

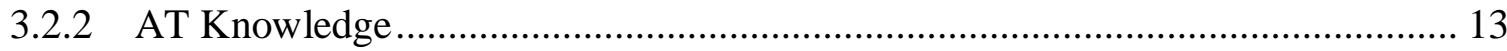

3.2.3 Administrative Support for AT ………………............................................ 14

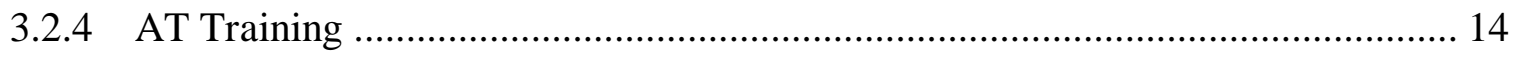

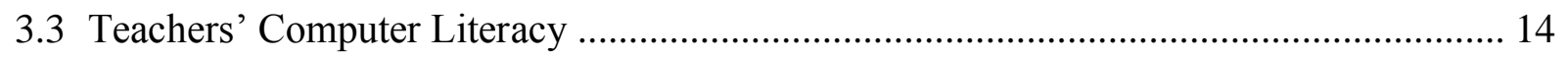

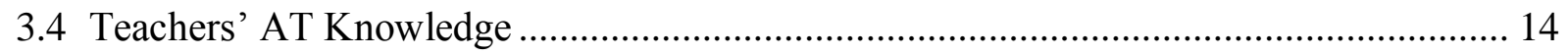

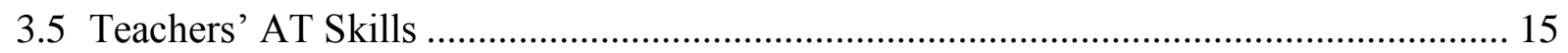

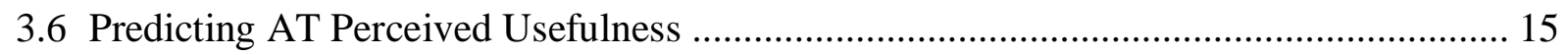

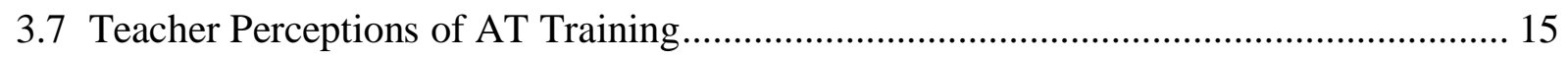

3.8 Teacher Perceptions of AT Resources and Support ......................................................... 16

3.9 Other Factors Influencing Use of AT ……………................................................... 16

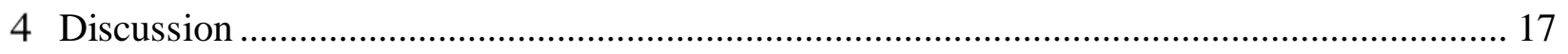

4.1 Factors Affecting Implementation .......................................................................... 19

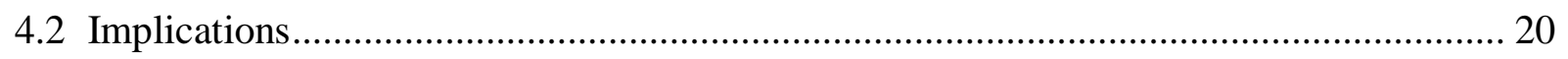

4.3 Limitations and Future Directions .............................................................................. 22

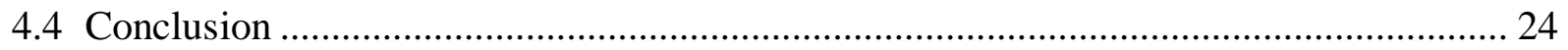

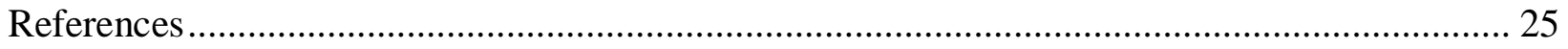

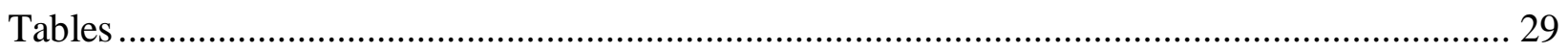

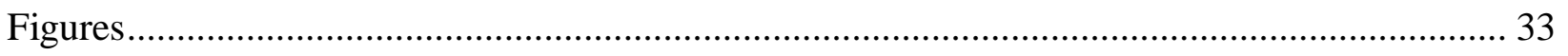

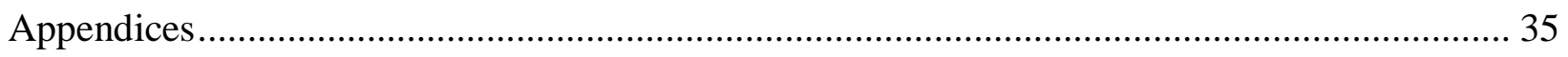




\section{List of Tables}

Table 1: Pearson's Product Moment Correlations for Years of Teaching with Computer Literacy and Average AT Skills

Table 2: Qualitative Thematic Analysis and Frequencies

Table 3: Factors that Discourage or Encourage the Use of AT in the Classroom

Table 4: Internal Consistency Analysis 


\section{List of Figures}

Figure 1. Orientations of perception of support and themes related to AT orientation.

Figure 2. Common problems with technology compared to AT evident in participants' qualitative responses. 


\section{List of Appendices}

Appendix A: Survey Items. 


\section{Introduction}

Assistive Technology (AT) is any technology that allows an individual with a disability to increase, maintain, or improve their functional capabilities (Edyburn, 2000). AT has been deemed a critical component of inclusive education (e.g., Edyburn, 2006; Zhou, et al., 2012) and the academic success of students with learning disabilities (LDs) as it can help them circumvent areas of challenge and complete tasks more efficiently and independently (Maor, Currie, \& Drewry, 2011; Morrison, 2007). In the last 15 years there has been an enormous increase in the availability of computer-based AT. These ATs include, but are not limited to, programs that can convert printed text to voice (text-to-speech), that can help students organize their writing (graphic organizers), and that can convert information spoken by students into text on their screen (voice recognition). It is important to note that not all AT is high tech (e.g., glasses, wheelchair), but for the purpose of the present study AT will refer to those technologies that are computer based.

Although AT is an important component of the academic success of students with LDs, it is often abandoned or inconsistently implemented (Phillips \& Zhao, 1993). In fact, some researchers estimate 30\% abandonment of technology devices (Zapf, Scherer, Baxter, \& Rintala, 2016). Despite there being little to no research on student perspectives of AT, there has been some research examining the perspectives of teachers when it comes to the implementation of AT in the classroom. Researchers have begun to isolate the factors impacting technology abandonment from a teacher perspective but have yet to clarify and confirm these factors. This previous research has mainly focused on teachers of students with visual and/or hearing impairments (e.g., Kamei-Hannan, Howe, Herrera, \& Erin, 2012; Zhou, et al., 2012). However, few studies have examined the perspectives of general education teachers or teachers of students with LDs. According to the research (e.g., Zapf et al., 2016), teacher perceptions and training in AT may play a role in its implementation. Therefore, it is important to clarify what variables impact teacher perceptions of AT in order to best support students with LDs in the classroom. The present study sought to answer the following research question: What variables contribute to teachers' perception of usefulness of AT? The purpose of this study was to understand teacher 
perceptions of computer-based AT tools and to determine what factors are correlated with perceived usefulness of AT.

\subsection{AT and Learning Disabilities}

According to Statistics Canada, 2.3\% of Canadian children have an LD (Statistics Canada, 2012), though other reports estimate that it is as high as 9.3\% (Altarac \& Saroha, 2007). Students with LDs experience impairments in academic skills which often co-occur with one another (e.g., reading and writing) and with other social skill deficits, and emotional- (e.g., Generalized Anxiety Disorder) or behavioural- (e.g., Attention Deficit-Hyperactivity Disorder) disorders (Lyon, 1996). Students with LDs often require a number of accommodations in the classroom to circumvent their specific academic skill deficits and may experience frustration or decreased academic self-concept (Zeleke, 2004).

LDs are "hidden disabilities," meaning that unlike many physical disabilities teachers and other students are not aware of LDs unless they are told about them (Lovett, Nelson, \& Lindstrom, 2015). This often results in students with LDs being told to "try harder" instead of providing these students with the necessary accommodations. When students with LDs are identified they are often included in the regular classroom with some support. This support may be provided through accommodations, remediation, program modifications, or a combination of the three approaches (Edyburn, 2006).

AT is considered a compensatory approach, in which the accommodation of AT circumvents the student's area of challenge or specific skill deficit. According to Blackhurst (2005), any technology that is necessary to aid a student in meeting their Individual Education Plan (IEP) or curriculum goals is an AT. AT is typically provided when students are not able to meet the academic goals that are laid out for them (Maor et al., 2011). For example, voice recognition software, which allows an individual to speak to a computer using a microphone and records the individual's voice as written text, may be provided to students when their struggles with spelling are keeping them from writing passages of sufficient length or quality. AT is designed to allow students to gain independence and is typically meant to be a tool that individuals with LDs can use throughout their life (Edyburn, 2006). AT is expected to provide flexible learning 
experiences and supports for students, but it is critical for schools and teachers to provide the appropriate environment in which students can use AT to be successful (Sider \& Maich, 2014).

There has been much research evaluating the effectiveness of the various AT tools that are available to individuals with disabilities. For example, Higgins and Raskind (1995) found that writing quality was the best when students were asked to write essays using voice recognition software than when they had no assistance or a human transcriber. DiCecco and Gleason (2002) found that when students were provided with graphic organizers (which allow for the visual representation of knowledge, concepts, or ideas), they demonstrated improvements in reading comprehension when compared to students who did not use a graphic organizer. Evmenova, Graff, Jerome and Behrmann (2010) found that spelling errors decreased, and that total number of words written increased when participants used word prediction software (which provides a list of predicted words as the individual types each letter) than when they did not use word prediction. It is important to note that simply providing AT to students with LDs does not guarantee its effective use (Forgrave, 2002), which may be why AT abandonment is so common.

\subsection{Abandonment of AT}

McIntosh (2010) has suggested that students abandon AT for a variety of reasons, including lack of training, perceived stigma, the self-perception that they are cheating, the effort required, previous negative experiences with AT, and the stages of grief surrounding their diagnosis of an LD. This idea, however, is not empirically based. McIntosh's observations are derived from her experience working with individuals who use AT, and while this does not invalidate her conclusions, there is no indication of how generalizable these suggestions are. Sharpe (2010) surveyed and interviewed K-12 teachers who had used AT in order to understand teacher perceptions of AT and reasons for AT abandonment, and found that initially teachers use AT because they perceive it as valuable for their students. Consequently however, lack of time and of technical training and support problems often lead to the discontinued use of AT in their classrooms. A strength of the study is that teachers across the state of Georgia were surveyed, therefore it was likely a representative sample that captured the state of AT use and abandonment for all the teachers in Georgia.

Zapf et al. (2016) found that students who used AT more often were more likely to have teachers who were comfortable with and interested in using AT and this teacher comfort with AT seemed 
to have the greatest impact on whether students who were assigned AT would actually use it (Zapf et al., 2016). Therefore, it appears that teachers who have more knowledge of AT may actually impact their students' use of AT in the classroom. Lee and Vega (2005), similarly, found that the largest barrier to AT use was lack of teacher training on AT. In their study, only $24.7 \%$ of teachers reported that their teacher education programs had provided them with adequate training on AT. Additionally, Lee and Vega found that those teachers who had received more training in AT were more likely to report that AT played an important part in the daily routine of their students. However, this finding is likely confounded by the fact that teachers who have students with more severe AT needs are probably more likely to be sent to AT training in the first place. It is unclear whether this finding represents the perceptions of general classroom teachers. Lee and Vega did not include open-response items asking participants to elaborate on their responses. In addition, the authors did not ask whether training was required or selfselected; they failed to ask for specifics that could have made their findings clearer. Flanagan et al. (2013) reported similar concerns with AT implementation to those reported by Lee and Vega (2005), but also found that among special education teachers, confidence, knowledge, access to AT, and experience with AT encouraged the implementation of AT.

Researchers have begun to isolate the factors impacting AT abandonment from a teacher perspective but have yet to clarify and confirm these factors. These previous studies suggest that a number of teacher factors, including perceived usefulness and AT knowledge, impact student use of AT in the classroom. The present study was designed to contribute to the knowledge base of AT in a number of ways. First, there are few, if any, current studies examining the state of use and teacher perceptions of AT for students with LDs or even more general special education. In fact, most research that has been completed focuses on students with motor or visual-perceptual impairments (e.g., Kamei-Hannan et al., 2012). Second, few studies have employed mixed methods designs, which can allow for a systematic understanding or inquiry of participants' attitudes and how they conceptualize the questions that they are being asked (Bergman, 2010). Including qualitative data collection in this design adds for a deeper understanding of teacher perspectives of AT and allows for teachers to expand on their perceptions beyond the content of the questionnaire; it allows for a more comprehensive and enriched portrait of the concepts being studied (Cook, 1986). It is possible that previous designs missed some factors influencing teachers' perceptions of AT simply because teachers did not have the option to provide more 
information. Finally, previous studies have focused on an American context and have not made it clear how their results can generalize to different contexts where laws and policies surrounding AT may be different.

\subsection{Teacher Perceptions of Technology}

Educational technologies differ from AT in that they simply refer to any technology implemented in the classroom, rather than one implemented to circumvent a specific deficit. Much of the research on teacher perceptions of technology focuses on educational technologies, or "general use of technology in the classroom" (e.g., Mundy, Kupczynski, \& Kee, 2012; Leech, 2011).

Leech (2011) found that teachers perceived technology to be an advantage for students' learning, but that they often did not use it to its full capacity. In her survey sample, teachers experienced extreme difficulty when attempting to integrate technology due to hardware and software problems (e.g., computer "crashes"). Additionally, Leech found that teacher training around technology typically focused on mechanics, but that teachers would benefit from more instruction on high-level topics, such as technology integration. Other authors have found that many teachers lack the necessary knowledge and technical proficiency to integrate technology in their classrooms (Mundy et al., 2012), a finding that is often expressed in the AT literature (Kamei-Hannan et al., 2012). Finally, some studies have found that lack of administrative support (e.g., principals, education superintendents) for teachers in integrating technology and AT in their classrooms can be a factor in AT implementation or lack thereof (Copley \& Ziviani, 2004).

The variables that will be examined in the present study include computer literacy, AT knowledge and training, administrative support for AT, and perception of usefulness of teachers. They will be discussed below in turn.

\subsubsection{Computer Literacy}

Computer literacy involves one's understanding of how to use computers and can include how to turn on the computer, how to use particular software tools for their intended purpose, and how to create and communicate using computers (Abtahi \& Motallebzadeh, 2016). For teachers, computer literacy includes the skills that allow them to use computers comfortably as 
instructional tools (Watt, 1980, as cited in Roberson, 2001). Teachers' computer literacy can affect their technology use in class (Kretschmann, 2015).

Roberson (2001) surveyed teachers of students with hearing impairments to better understand teacher competencies with computers and the barriers to implementation of computers within the classroom. The author found that only six of the required 20 technology competencies (e.g., using computer-related terminology) for teachers of students with hearing impairments were actually taught during teacher education programs, and that although faculty supported these competencies they did not model these competencies during their instruction. It seems, therefore, that teachers were expected to have technology competencies for which their teacher training programs did not prepare them. Teachers' computer literacy is important in the context of AT because in order to properly implement AT, teachers must understand how the AT can be used and how to troubleshoot student problems with computers quickly. Further, difficulties with computer management or fixing technical difficulties has been cited as a common barrier to technology implementation (Copley \& Ziviani, 2004). Beyond basic computer literacy, teachers must also understand how to effectively implement AT within the classroom environment (Copley \& Ziviani, 2004). Margolis and Goodman (1999) suggested that teachers often feel as though they receive training on the very basic functionality of AT equipment, but that they miss out on understanding the best practices for implementation in their training.

\subsubsection{AT Knowledge and Training}

In a survey of over 800 teachers from 50 states in the United States of America, Zhou et al. (2012) found that $59.3 \%$ of teachers reported no to some confidence with AT (on a 5-point Likert scale ranging from "no confidence" to "very confident"), regardless of the perceived usefulness of AT for their students. The authors also found that younger teachers were typically more confident with using AT than older teachers, and that, in general, participants were most confident when they were able to collaborate with other teachers when using AT (Zhou et al.). This study suggests that teachers are not confident with their AT abilities. This finding is important when considering actual use and implementation of AT, as teachers who perceive AT to be effective for students with high-incidence disabilities, like LDs, and who are confident using the AT themselves are more likely to implement it (Flanagan, et al., 2013). 
Mundy et al. (2012) found that teachers who were trained extensively on technology implementation were more likely to implement the technology effectively, and that teacher training is in fact the most important factor in technology implementation. In this study, teachers were trained using the TeachUp! Project, which provides teachers in high needs schools with the opportunity to engage in an internship program to increase their proficiency in AT. The internship included one-on-one coaching and training and was described as a technology empowerment program (Mundy et al.). Teachers were also provided with ongoing support for technology implementation.

Maushak, Kelley, and Blodgett (2001) examined the impact of a one-session teacher training intervention on the attitudes and knowledge of teachers about AT. During the intervention, definitions of AT and the laws surrounding AT in the classroom were reviewed, AT was shown and demonstrated, and applications of the AT for specific disabilities were discussed. Teachers were also able to explore the devices. The authors found this one-session intervention did not significantly change teacher attitudes toward AT but did improve their knowledge. They concluded that teachers need more intensive AT training interventions (Maushak et al., 2001).

In another study looking at teacher training and AT use, Kamei-Hannan et al. (2012) found that when teachers completed a one- to two-week intensive course on AT which included more than 100 lessons on 12 different AT devices they felt more comfortable using AT with their students. These lessons used hands-on learning, lectures, simulations, and partner practice on instructional strategies, as well as a number of assignments (Kamei-Hannan et al.). The authors also found that following the intervention teachers were more likely to seek out additional training in AT.

Thus, the research indicates that teachers do not inherently have negative perceptions of AT, but that they require extensive training in order to feel confident in implementing AT with their students.

\subsubsection{Administrative Support for AT}

Although teachers are the focus of the present study, some authors have suggested that administrative support, for example from school principals or AT decision-makers, is related to teachers' and ultimately students' use of AT in the classroom (e.g., Edyburn, 2000). Schlosser et al. (2000) trained a multidisciplinary team of professionals on AT that was required for one 
particular student and measured the impact of the training. This study also included a targeted AT strategy, which allowed the team of professionals to systematically identify and decrease barriers to use of AT. The results suggested that training the school team allowed for the effective integration of the AT and promoted student participation, suggesting that a targeted approach, involving all team members may be effective (Schlosser et al., 2000). This study required the participation of all of the individuals who work with the student, including the school administration. It should be noted that this study was supported by researchers and therefore may not reflect the type of support that is typically available to teachers. It is important to clarify the type of support that teachers receive in the context of the present study in order to better understand the contribution of administrative support to teachers' perceived usefulness of AT.

\subsubsection{Perception of Usefulness of AT}

Nam, Bahn, and Lee (2013) used structural equation modeling analysis to evaluate the biggest factor impacting AT usage in the classroom compared to general technology usage. The authors found that the factors influencing AT abandonment were quite different from for general technology. Nam et al. (2013) suggested that there are many unique characteristics of AT compared to general technology, such as unfamiliar usage and necessity for daily life. They also found that result demonstrability (i.e., the AT does what you want it to do and you know how to make the AT do it) affected perceived usefulness of AT. Therefore, it seems that the function of AT was a major factor in its continued use. Nam et al. also found that previous result demonstrability affected the likelihood that teachers would use the AT again in the future; if the AT was too hard to use, they did not use it again. Given that teachers' attitudes and perceptions are a key factor for AT implementation, it is important to ensure that the system governing AT use in the classroom is set up in a way to ensure that teachers have the best possible chance of understanding the AT when they are first exposed to it.

\subsection{Objectives and Hypotheses}

Given the variety of research that has been completed on the topic of AT, there is still not a satisfying answer to the research question of the present study: What variables are related to teachers' perception of usefulness of AT? It is clear that students with LDs benefit from AT, that students are abandoning AT at high rates, and that teacher perceptions of AT can impact student 
use but is it not clear what variables are related to teachers' perceived usefulness of AT and how these variables are related to each other.

The current study had four objectives. The first objective was to determine which of the independent variables (computer literacy, AT knowledge, AT training, administrative support) were related to the dependent variable (perceived usefulness of AT). It is expected that higher levels of computer literacy will be related to higher levels of perceived usefulness because as Copley and Ziviani (2004) found, difficulties with computer management or fixing technical difficulties has been cited as a common barrier to implementation of technology. Based on Lee and Vega's (2005) findings that teachers who had greater self-perceived knowledge of AT were more likely to report that AT was an important part of the daily routine for their students, it is expected that teachers who have higher levels of self-perceived AT knowledge will have higher perceived usefulness of AT. Next, understanding that teachers require training in order to feel competent with AT, it is expected that teachers who have received more training on AT will have more positive perceptions of using it in their classroom and will use it more frequently, whereas teachers who have received little training will have more negative perceptions. It is expected that higher levels of administrative support will be related to higher levels of perceived usefulness, based on Schlosser et al.'s (2000) design, which demonstrated highly effective AT integration in the context of a supportive, multidisciplinary team. The second objective was to determine whether younger teachers had higher levels of computer literacy or AT knowledge than older teachers. It is expected that younger teachers will have higher perceived computer literacy, as they are more likely to have grown up using computers. Younger teachers are more likely digital natives than their elder counterparts, though older teachers may have had more opportunities for training on AT and therefore may had more AT knowledge than younger teachers. The third objective is to understand how teachers view administrative support at their school. Finally, the fourth objective is to determine what factors teachers report as hindering their use of AT in the classroom.

\section{Method}

A concurrent complimentary mixed methods design was chosen to examine the previously cited research questions. An online survey of Ontario teachers of grade 6 to 10 students was conducted to learn about use of and perspectives on using assistive technology (AT) in classrooms. The 
purpose of this study design was to attain data with a low response time and at a low cost. The survey included a mix of open- and closed-ended questions with dominance of closed-ended questions (QUAN + qual). The purpose of including open-ended questions was to deepen and elaborate on the current understanding of teacher perceptions of AT based on previous research findings. The design also allowed teachers to provide more comprehensive information about factors influencing their use and perceptions of AT in the classroom beyond what has been previously studied.

\subsection{Participants and Procedure}

Grade 6 to 10 Ontario Certified Teachers were invited to participate in the study through an email sent to the Learning Disabilities Association of Ontario chapters, the Association for Special Education Technology, and graduates from the Master of Education and Master of Arts in Child Study and Education programs at the Ontario Institute for Studies in Education. In total, 33 teachers responded to the survey, one teacher was excluded because she did not meet inclusion criteria, and eight participants did not complete the survey or withdrew before completion of the survey (Appendix A). In total, data from 24 teachers (92\% female, $8 \%$ male) were included in the analysis. On average teachers had been teaching for 9 years $(M=9.09, S D$ $=8.85$ ) with a range from 0 to 35 years of teaching. As teachers were required to be certified, 0

years of experience indicates a teacher's first year on the job. A majority of teachers had taken an Advanced Qualification course focusing on Special Education (70.8\%).

\subsection{Measures}

The online survey (Appendix A) was developed by the researcher on Qualtrics (www.qualtrics.com), a secure online service provider for the creation of professional online surveys. The survey consists of 155 open- and closed-ended items to elicit information about teachers' AT knowledge and training, their perception of support with AT, basic computer literacy, their perception of the usefulness of AT, and the factors that encourage or discourage AT use in the classroom. The survey items were adapted from measures that were previously empirically validated. The measures gathered through the survey are outlined below in turn. 


\subsubsection{Demographic Information}

The first section of the survey asked about basic demographic characteristics: age, sex, cultural background, time spent teaching, and where in Ontario the teacher works. Most items included button options as well as an 'Other' option, which provided an open-response option. There were also items related to the composition of their class (e.g., number of students with IEPs, number of students who use AT).

\subsubsection{AT Knowledge, Training, and Perception of Support}

Items from a study by Lee and Vega (2005) relating to school administration support and teachers' perception of their technology abilities were adapted to focus on AT. These twenty-one items included: "AT Information is easy to obtain in my school district" and "I can arrange and manage the classroom environment to facilitate AT use." Responses were on a 5-point Likert scales ranging from 'strongly disagree (5)' to 'strongly agree (1)'. Other items related specifically to teachers' educational experiences with AT (e.g., teacher's college, conferences) were also included in order to better understand the nature of teachers' AT training. For example, teachers were asked to rate their skills on a 5-point Likert scale for a number of AT products from 'none' to 'advanced'.

\subsubsection{Technology Equipment and Computer Literacy}

Fourteen questions elicited information about participants' use of and access to technology, and their computer literacy. These questions included a variety of response types: open response, Likert scale, and multiple choice. For example, participants were asked: "How many minutes a day do you spend using technology?"; "How would you rate your basic computer skills?"; and "How many years have you been using computers?"

\subsubsection{Perception of Usefulness}

Nine questions were adapted from Nam, Bahn, and Lee (2013). These questions related to AT use in the classroom and the benefits or drawbacks of using AT according to teachers. For example, participants were asked: "The performance of my student is improved by using the technology."; and "I think the technology would be easy to use." These items included a 5-point Likert scale from 'strongly disagree' to 'strongly agree'. These items were included as an 
outcome measure of teacher perceptions of AT. Specifically, to measure the outcome "Is AT useful for my students?"

\subsubsection{Factors Influencing the Use of AT}

Two questions address the factors that would encourage or discourage the use of AT in the classroom: "Please indicate which of the factors below DISCOURAGE technology use in your classroom by students with special education needs" and "Please indicate which of the factors below ENCOURAGE technology use in your classroom by students with special education needs." These questions were from Flanagan et al. (2013) and required participants to select as many factors that applied to them from a list of 12 options. Participants were also asked: "Are there any other factors that help or hinder use of the assistive technology in your classroom?" in an open response format.

\subsection{Data Analysis}

Internal consistency was assessed using Cronbach's Alpha for each subscale and it was determined to be acceptable (Table 4).

To examine the main research question, namely, 'What variables are related to teachers' perceived usefulness of AT?' Pearson correlational analyses were conducted to investigate whether the independent variables (computer literacy, AT knowledge, AT training, administrative support) were related to the dependent variable (perceived usefulness of AT). A linear regression was also conducted to investigate whether or not the independent variables that were significantly correlated with perceived usefulness of AT (computer literacy and AT knowledge) predicted the dependent variable (perceived usefulness of AT) and to determine the contribution of each variable to predicting perceived usefulness of AT.

To investigate whether younger teachers have greater computer literacy or AT knowledge, Pearson product-moment $\mathrm{r}$ correlations were conducted to assess the relationship between years of teaching and computer literacy, and years of teaching and AT knowledge. Pearson $r$ correlation is a bivariate measure of association (strength) of the relationship between two variables (Statistics Solutions, 2013). Given that all variables are continuous (interval data) and the hypotheses sought to assess the relationships, or how the distribution of the $\mathrm{z}$ scores varied, Pearson $r$ correlations are the appropriate bivariate statistic (Statistics Solutions, 2013). 
A qualitative thematic analysis was also used to analyze survey data from open-ended items. Frequencies and percentages were calculated for these open-ended responses and ranked items to determine the factors that teachers reported as hindering their use of AT in the classroom.

\section{Results}

The results of the present study indicated a number of interesting findings. Teachers had diverse views on AT implementation and a variety of experiences with and knowledge of AT.

\subsection{Characteristics of Study Participants and Their Students}

A large majority of the teachers in the present sample were currently teaching at least one student with an IEP $(91.7 \%)$. There was an average of 8 students with IEPs per teacher $(M=8.00, S D=$ 6.63), with a range of 2 to 25 students. One teacher reported that she taught a special education class in which all 25 of her students had IEPs, but the most common response was 2 students with IEPs $(n=4)$. A smaller majority of participants also reported that they were currently teaching students with personal AT provided by the school (70.8\%), with an average of 3 students with individual AT provided by the school per teacher $(M=3.32, S D=3.99)$.

\subsection{Variables Related to AT Perceived Usefulness}

Pearson correlational analysis were used to determine which variables (computer literacy, AT knowledge, administrative support for AT, and AT training) were related to perceived usefulness of AT.

\subsubsection{Computer Literacy}

The analysis revealed that there exists a significant positive linear relationship between computer literacy and perceived usefulness of AT, $\mathrm{r}=.55, \mathrm{p}=.010$. That is, the population correlation is significantly different from zero. If can be inferred that, in the population, teachers who have higher levels of computer literacy perceive AT to be more useful.

\subsubsection{AT Knowledge}

The analysis revealed that there exists a significant positive linear relationship between AT knowledge and perceived usefulness of AT, $r=.81, p<.001$. That is, the population correlation 
is significantly different from zero. If can be inferred that, in the population, teachers who have higher levels of AT knowledge perceive AT to be more useful.

\subsubsection{Administrative Support for AT}

The analysis revealed that there was not a significant linear relationship between administrative support for AT and perceived usefulness of AT, $r=.43, \mathrm{p}=.058$. That is, the population correlation is not significantly different from zero. If can be inferred that, in the population, teachers who have higher levels of administrative support for AT do not perceive AT to be more useful.

\subsubsection{AT Training}

The analysis revealed that there was not a significant linear relationship between AT training and perceived usefulness of AT, $r=.15, p=.504$. That is, the population correlation is not significantly different from zero. It can be inferred that, in the population, teachers who have more training experiences do not perceive AT to be more useful.

\subsection{Teachers' Computer Literacy}

Teachers had, on average, intermediate computer literacy as measured by their self-reported level of competency with a number of common computer skills and applications (i.e., the internet, typing, word processing programs, spreadsheets, databases, presentation software, multimedia applications, web design, search engines, email and graphics applications; $M=3.11, S D=.56$ ). It was expected that teachers with fewer years of experience would have higher levels of selfreported computer literacy; however, years of teaching was not significantly correlated with computer literacy, $r=.03, p=.905$ (Table 1).

\subsection{Teachers' AT Knowledge}

Teachers had, on average, intermediate AT knowledge as measured by items from Lee and Vega's (2005) 5-point Likert AT Knowledge and Skills scale (Appendix A); $M=2.92, S D=$ .88). It was expected that teachers with fewer years of experience would have higher levels of self-reported AT knowledge; however, years of teaching was not significantly correlated with AT knowledge, $r=.23, p=.226$ (Table 1$)$. 


\subsection{Teachers' AT Skills}

Despite all teachers meeting at least basic computer literacy, teachers' self-reported average skills on a number of AT tools were in the poor range. Therefore, computer literacy was not significantly correlated with AT skills, $r=.15, p=.509$. Additionally, in this case although it was expected that teachers with fewer years of experience would be more proficient on AT, years of teaching was significantly positively correlated with AT skills, $r=.48, p=.023$ (Table 1). Therefore, it appears that the longer teachers have been teaching the greater their proficiency with AT. There was only one teacher who reported greater than 'fair' AT skills on average. This individual had 14 years of experience and reported the greatest knowledge of AT, though they did not report greater than average training experiences.

\subsection{Predicting AT Perceived Usefulness}

Given the two significant correlations with perceived usefulness (computer literacy and AT knowledge) a multiple linear regression was performed to explore the relationship among computer literacy and AT knowledge, as predictor variables, and perceived usefulness of AT (Nam, Bahn, \& Lee, 2013), as the predicted variable. Results indicated that the overall model was significant, $\Delta R^{2}=.66, \Delta F(1,19)=36.61, p<.001$. AT Knowledge alone predicted $65.8 \%$ of the variance in the teachers' perceived usefulness of AT, $b=.81, t(19)=6.05, p<.001,95 \% \mathrm{CI}$ $[.45, .99], r_{\text {part }}=.81$, Tolerance $=1.00$, with computer literacy not significantly contributing to the model. A Pearson correlational analysis revealed that there was a significant linear relationship between computer literacy and AT knowledge, $\mathrm{r}=.58, \mathrm{p}=.003$. Therefore, it can be concluded that the items related to computer literacy did not add any significant predictive power to perceived usefulness in addition to AT knowledge. Overall, the results indicated that AT knowledge significantly predicts teachers' perceived usefulness of AT.

\subsection{Teacher Perceptions of AT Training}

A qualitative analysis of participants' problems with implementing AT in the classroom revealed that lack of training on the use of AT was one of the most common problems, indicated by $33.3 \%$ of participants who provided answers to open-ended items (Table 2). In addition, only 29.2\% of participants recalled learning about AT during their teacher education program. Almost half of the participants (45.8\%) had attended at least one conference or talk focusing on AT. 
Therefore, it appears that despite some opportunities to learn more about AT (e.g., conferences), teachers are reporting that they need additional training on AT. An interesting observation from the qualitative responses focusing on AT training is that the majority of teachers who discussed AT training (4 out of 6) focused on student training rather than their own knowledge and skills. Two teachers highlighted a lack of professional development opportunities when it comes to AT (e.g., "I feel by the time I am comfortable using one AT program, the board is encouraging a different program, or an alternative. I find it is hard to keep up with the number of AT programs and apps; especially when considering we receive very little training about how to use these programs."; Table 2).

\subsection{Teacher Perceptions of AT Resources and Support}

AT resources were analyzed using quantitative data from Lee and Vega's (2005) 5-point Likert Resources scale obtained in this study. Teachers were generally neutral, but on the side of agreement that they had access to enough AT resources $(M=3.40, S D=.79)$. However, when reporting on general technology lack of access was the most common response, indicated by eleven teachers (Table 2).

Teachers quantitatively reported relatively neutral responses when asked how supportive the administration of their school was when it comes to AT on a 5-point Likert scale ranging from "strongly disagree" to "strongly agree" $(M=3.45, S D=1.06)$. When participants were qualitatively asked about their administrative support of AT, half had positive orientations, or focused mainly on positive themes (Figure 1). For example, one teacher reported that "they are receptive to change and [would] fund the use of technology if needed by teachers or students."

Other teachers had less positive experiences with the administration at their schools; "We do not have a go to person to help with integrating technology. We have very limited access to technology..." Further, little support on how and when to use AT was the most common response when teachers were asked to rank the factors that discourage their use of AT, with $20.8 \%$ of teachers ranking this as the most important reason (Table 3 ).

\subsection{Other Factors Influencing Use of AT}

The most common theme that appeared when teachers were asked about what common problems they have with implementing AT in the classroom were student factors (Table 2). These factors 
included student motivation, stigma, students not charging their devices, misuse of AT, and other logistical factors. Time was another common theme indicated by teachers. Teachers reported, "lack of planning/prep time to adequately support students using AT for [their] lessons..." and that they "...don't have time to help with problems while teaching a whole class." (Figure 1). Overall, there were many reported difficulties with implementation; however, when teachers were asked to rank the most important factor that would encourage their use of AT in the classroom, assisting students individually or providing differentiated support was the most common response indicated, with $45.8 \%$ of teachers selecting this response (Table 3 ).

Another interesting observation was that teachers reported different concerns when discussing regular technology compared to AT. Themes present in teacher responses about regular technology focused mainly on internet speed, access to technology (e.g., number of devices available to students), software, and the physical hardware available, whereas when asked about AT teachers focused on student factors and student training as the major difficulties. Therefore, it appears that AT brings its own, unique challenges when being implemented in the classroom.

\section{Discussion}

Zhou et al. (2012) found that among teachers of students who have visual impairments, younger teachers were more confident using AT and had more positive perceptions of AT. It was, therefore, expected that teachers who had been teaching for the fewest number of years would have the greatest computer literacy and AT skills, but this was not the case. In fact, computer literacy was not significantly related to years of teaching. Perhaps this finding was impacted by the fact that participant years or teaching, and not age, was collected in the present study.

The results of the present study demonstrate that AT knowledge alone predicted perceived usefulness of AT despite the fact that computer literacy is significantly correlated with perceived usefulness of AT. Given that AT knowledge is positively correlated with years of teaching it appears that the more years of teaching experience a teacher has, the more exposure to or the more opportunities they have to learn about AT. This finding appears to be in contrast with the findings of Zhou et al. (2012), who suggested that younger teachers may be more confident using AT because their teacher preparation program included training in AT whereas older teachers' training did not. Perhaps the teacher training programs attended by the participants in this study are not providing teachers with the necessary AT skills and instead teachers are receiving this 
training on the job. Given that fewer than $30 \%$ of teachers in this sample reported any exposure to AT during their teacher training program, this result is unsurprising. It is also possible that teachers with more years of teaching experience have had more exposure to working with students with LDs and appreciate the impact or potential of using AT with their students. Teachers with more years of experience may be more proficient with classroom management strategies or other aspects of managing as a classroom teacher and are more comfortable with learning how to use AT and manage it for those students who require it.

Respondents reported that student factors and lack of AT training were their biggest barriers to AT implementation; however, the quantitative results demonstrated that AT knowledge, rather than training experiences themselves, correlated with perceived usefulness. The majority of teachers focused on student training in their responses, perhaps indicating that although teachers in general reported a need for more training experiences, their perception was that the responsibility for understanding how to operate AT should rest on the students who are using it. As it stands in Ontario, students typically receive short bursts of training on AT (e.g., 3 hours total) and following this training they are expected to use the AT independently and appropriately in the classroom. Given that teachers have reported lack of training as a barrier, that AT knowledge predicts perceived usefulness of AT, and that previous studies have found that short-term interventions were not sufficient for teacher training (e.g., Kamei-Hannan et al., 2012; Maushak et al., 2001), it follows that they would not be wholly successful for students. Overall, there may be a disconnect with the amount of training that teachers think students need compared with how much training they think that they need. It appears that teachers may perceive students as being responsible for learning how to use AT in the classroom, but perhaps this finding indicates a lack of support for teachers and students in implementing AT in the classroom environment, and that it is unclear to teachers where the responsibility should lie.

Even though years of teaching experience was positively correlated with AT knowledge, teachers in general still reported a lack of knowledge about AT. Perhaps this echoes the finding by Margolis and Goodman (1999) that teachers often feel that they are only being trained on the basic functionality of the AT, rather than on effective implementation strategies. Given that teacher training experiences, as reported by exposure during teacher training programs and attendance at talks or conferences about AT, was not significantly correlated with perceived usefulness, the question of where teachers are gaining their AT knowledge remains. This is an 
area that requires greater research inquiry; what types of training experiences are teachers receiving and what is the content of those experiences?

The present study found that perceived administrative support does not significantly correlate with perceived usefulness of AT, and further no teachers reported that administrative support contributed to their implementation of AT in the classroom (Figure 2). However, previous researchers found that administrative support for AT was a factor in its implementation (Copley \& Ziviani, 2004). Further, 'little support on how and when to use AT' was the most commonly selected option when they were asked was factors discourage the use of AT in the classroom, which appears to be in contrast with the above results. Perhaps teachers conceptualized support beyond just the administrative angle within the other studies or scales. In the qualitative data some teachers reported that they would benefit from a go-to support person within the school to aid in AT implementation, which would appear to align with this thinking. It appears that teachers are not looking to administrative staff for support with AT. Rather they value the guidance of other professionals, like AT consultants.

Overall, the results of the present study replicate previous findings, but a number of factors that were expected to correlate with perceived usefulness of technology were not significant (i.e., support for AT, and AT training). In some ways this finding actually helps to clarify the findings in previous research and provides a clear direction toward intervention. Specifically, there is a clear need for greater AT knowledge among teachers, especially those teachers who are early in their career. A focus on AT should be included in pre-service teacher education programs and teachers should be provided professional development on AT throughout their career. Classroom implementation strategies should be included in teacher education about AT. These could include relevant elements of classroom management and how to support learners with a variety of AT needs. It is also possible that there was a lack of power in the present study due to limited sample size, which may have impacted the results.

\subsection{Factors Affecting Implementation}

On items previously used by Flanagan et al. (2013), teachers in this sample reported that 'little support on how and when to use AT' was the most important factor discouraging use of AT, whereas 'assist students individually or providing differentiated support' was the most important factor encouraging use of AT in the classroom. Flanagan et al. found that 'costs' and 'increases 
students' learning in literacy' were the most important factors. Similar responses were reported to encourage AT use, but the factors discouraging AT use were very different. Only one participant in the current study mentioned cost as the most important discouraging factor. The participants in Flanagan et al.'s study were special education teachers, which would not appear to be very different from the participants in the present study, therefore these differences are intriguing. Perhaps the geographic location of Flanagan et al.'s study impacted these differences. In the present sample, AT is provided by the school to students who require it, but perhaps this is not the case where Flanagan et al. did their work. It appears that providing AT to students who require it within the school board has overcome the barrier of cost for use of AT in the classroom, but that now lack of support for AT has become another barrier. It is important for stakeholders to consider barriers to implementation when making decisions about AT.

The qualitative information provided by teachers provided rich data that led to a deeper understanding of the diverse and interacting phenomena that affect perceived usefulness of AT or its actual use in the classroom. One interesting finding was that teachers reported different concerns when asked about challenges implementing general technology compared to AT. For example, the most common concerns with implementation of technology were internet and access to devices, followed by software or hardware problems (Figure 2), which echoes Leech's (2011) finding that teachers experience extreme difficulty when attempting to integrate technology due to hardware and software problems. When asked about challenges implementing AT teachers reported lack of training, which was also reported to be a critical factor for successful implementation by Mundy et al. (2012). Teachers reported that student factors were the most common problems with implementation of AT (Figure 2). It is interesting that student factors were not reported to be important for implementation in other studies. Perhaps the items in other studies did not specifically address student factors. Without including the qualitative component in the present study no information about student factors would have been gained. However, given that there were many different responses coded under this theme it is worthy of future investigation.

\subsection{Implications}

The present study has clear and important implications for teacher training and in-service professional development. If knowledge of AT accounts for the most variation in perceived 
usefulness of AT, then it is important to provide teachers with many opportunities to increase their AT knowledge. These findings are supported by Maushak et al.'s (2001) and KameiHannan et al.'s (2012) studies which found that teachers need intensive AT training interventions in order to improve their AT skills. The majority of teachers who participated in this survey had a least one student with an AT device provided by the school at the time of survey completion, so they need to be aware of effective implementation strategies to best support their students. As almost $50 \%$ of teachers reported assisting students individually or providing differentiated support was the most important factor encouraging AT implementation into the classroom, this training is clearly important to both students and teachers. When considering training for implementation of AT, it will also be important to educate teachers on how to integrate these ATs into the classroom in a way that allows students with LDs to access the same curriculum material as their peers.

That said, student factors were found to be one of the most common challenges for teachers when integrating AT into the classroom. Without an understanding of these various student factors, teacher training and knowledge of AT may not make a difference in its implementation, especially if students are refusing to use it as some teachers reported. This demonstrates that a holistic approach in which the needs of all stakeholders is considered when implementation of AT. Schlosser et al. (2000) used a multidisciplinary approach in their case study in which all stakeholders' opinions and needs were considered and found that it allowed for the effective integration of the AT and promoted student participation. Perhaps this is the future of AT implementation.

Additionally, the data suggests that teachers perceive that students do not receive enough training on AT (as was discussed above). This has significant implications for the types of training opportunities that are being provided to students and teachers on AT. The type of training provided to these key stakeholders needs to take their preferences and voices into account in order to best support students who require AT. If teachers do not understand the AT tools that students are using, they will likely be unable to create an environment in which the tools are able to be used effectively by students.

Next, the finding that administrative support was not a significant correlate of perceived usefulness, but that qualitatively teachers reported that support was an implementation concern 
suggests that support can be conceptualized in a number of ways. It is possible that teachers' perception of AT usefulness is not affected by administrative actions (or inaction), but that administrative support may greatly affect actual implementation in the classroom, possibly due to access to resources or training opportunities for teachers. On the other hand, teachers may conceptualize support as separate from the support their administrators provide. The teachers who identified support as an implementation challenge did not specifically report on their administrators, but rather reported that an AT specialist, or go-to person, within the school would be beneficial in helping them troubleshoot problems. These different viewpoints suggest that teachers should be consulted when identifying support needs for AT and that simply providing funding for AT is not enough for successful implementation.

Overall, the implication of this research is that it will provide researchers and school board administrators with a deeper understanding of AT use in the regular classroom and how teacher perceptions may affect the use and uptake of new AT. Future implications may also include changes to teacher professional development or preservice training.

\subsection{Limitations and Future Directions}

Results of this study should be carefully interpreted because of the limited sample size. Only 24 teachers provided useable data. Due to the limited sample size, there could have been a lack of variability in responses to some items, leading them to not reach significance as predictors of perceived usefulness even though previous research found them to influence implementation (e.g., administrative support; Copley \& Ziviani, 2004). It is also possible that the recruitment procedures led to responses from a homogenous group of participants, who perhaps were more highly trained on AT than the average teacher. This could also contribute to a lack of variability in responses. Overall, the sample size of the present study may have contributed to a lack of power and dictates the need for replication with a larger sample.

Participant fatigue due to the number of items in the survey may have also contributed to a smaller sample size (Krosnick, 1999). A large proportion of teachers who initially followed the survey link did not respond to any survey items (24.2\%). Perhaps there could have been a more efficient measure or way to access the same information from teachers with fewer items. 
Additionally, while the qualitative data provided interesting findings and interpretations, there were some cases where interviewing teachers would have clarified some of the variables. For example, student factors was a common theme; however, it appeared to be very complex and deserving of greater investigation. Student motivation and students not charging their devices were both reported as concerns; however, it is not clear whether students are not charging their devices due to lack of motivation to use AT, due to simply forgetting, or due to some other factor. Future research should seek to clarify teacher perceptions of the student factors affecting effective AT implementation, as well as to directly include student participant voices.

Thus far research has focused on AT for individuals with physical disabilities (e.g., wheelchairs; Phillips \& Zhao, 1993) and university populations (Brown-Chidsey, Boscardin, \& Sireci, 1999), but there has been a limited amount of research in AT use by elementary or high school students with LDs. At the time of writing, no published research has directly looked at elementary and high school students' perceptions of using AT in the classroom. Given the results of the present study student perceptions of AT are predicted to play a major role in its successful implementation. A follow-up study to the present research would be useful in order to determine whether students have the same frustrations and challenges with AT as teachers or whether there are unique concerns from a student perspective. It would also be interesting to find out what is working for students and teachers when it comes to AT. A well-designed intervention study focusing on classroom implementation strategies for teachers would be another possible direction for future studies.

A more active approach to teacher AT knowledge transmission could be useful given the finding that greater teacher knowledge predicted greater perceived usefulness of AT. Developing and investigating a training program intervention informed by research that targets teachers' specific questions and challenges with AT implementation and knowledge could provide greater information to pre-service teacher training institutions in order to better prepare future teachers for their work with students with learning disabilities. As Kamei-Hannan et al. (2012) suggested, these training opportunities should be intensive, and as teachers in the present study suggested ongoing support should be offered outside of the training programs. Further, as Margolis and Goodman (1999) found, teachers are often only provided training on basic AT functionality, therefore future training should focus on best practices for implementation of AT. 


\subsection{Conclusion}

Results of this study suggest that AT knowledge correlates with teachers' perception of the usefulness of AT. There are also other barriers to implementation, including lack of training, student factors, and the software or devices themselves, though these factors require greater investigation. It is also clear that teachers are not receiving enough training on or exposure to AT during their teacher training and that changes to this preservice teacher education and professional development are warranted. Supporting students with learning disabilities is critical to their academic success, and in general AT is not being implemented in the most effective way. 


\section{References}

Abtahi, T., \& Motallebzadeh, K. (2016). Iranian EFL teachers' sense of professional identity and their computer literacy. International Journal of Applied Linguistics and English Literature, 5, 207-214.

Altarac, M., \& Saroha, E. (2007). Lifetime prevalence of learning disability among US children. Pediatrics, 119, 77-83.

Bergman, M.M. (2010). On concepts and paradigms in mixed methods research. Journal of Mixed Methods Research, 4, 171-175.

Blackhurst, A. E. (2005). Perspectives on applications of technology in the field of learning disabilities. Learning Disability Quarterly, 28, 175-178.

Brown-Chidsey, R. B., Boscardin, M. L., \& Sireci, S. G. (1999). Computer attitudes and opinions of students with and without learning disabilities (Doctoral dissertation). Retrieved from PsycINFO.

Cook, T. D. (1986). Postpositivist critical multiplism. In R. L. Shotland and M. M. Mark (eds.), Social science and social policy (pp. 21-62). Thousand Oaks: Sage.

Copley, J., \& Ziviani, J. (2004). Barriers to the use of assistive technology for children with multiple disabilities. Occupational Therapy International, 11, 229-243.

DiCecco, V. M., \& Gleason, M. M. (2002). Using graphic organizers to attain relationship knowledge from expository text. Journal of Learning Disabilities, 35, 306-320.

Edyburn, D. L. (2000). Assistive technology and students with mild disabilities. Focus on Exceptional Children, 32, 1-23.

Edyburn, D.L. (2006). Assistive technology and mild disabilities. Special Education Technology Practice, 8, 18-28. 
Flanagan, S., Bouck, E. G., \& Richardson, J. (2013). Middle school special education teachers’ perceptions and use of assistive technology in literacy instruction. Assistive Technology, 25, 24-30.

Forgrave, K. E., (2002). Assistive technology: Empowering students with learning disabilities. Assistive Technology, 75, 122-126.

Higgins, E.L. \& Raskind, M.H. (1995). Compensatory effectiveness of speech recognition on the written composition performance of postsecondary students with learning disabilities. Learning Disability Quarterly, 18, 159-174

Kamei-Hannan, C., Howe, J., Herrera, R. R., \& Erin, J. N. (2012). Perceptions of teachers of students with visual impairments regarding assistive technology: A follow-up study to a university course. Journal of Visual Impairment and Blindness, 106, 666-678.

Kretschmann, R. (2015). Effect of physical education teachers' computer literacy on technology use in physical education. Physical Educator, 72, 261-277.

Krosnick, J. A. (1999). Survey research. Annual Review of Psychology, 50, 537-567.

Lee, Y., \& Vega, L. A. (2005). Perceived knowledge, attitudes, and challenges of AT use in special education. Assistive Technology, 20, 60-63.

Leech, S. N. (2011). Teachers' perceptions of factors associated with technology integration (Doctoral dissertation). Retrieved from PsycINFO.

Lovett, B. J., Nelson, J. M., \& Lindstrom, W. (2015). Documenting hidden disabilities in higher education. Journal of Disability Policy Studies, 26, 44-53.

Lyon, G. R. (1996). Learning disabilities. The Future of Children Special Education for Students with Disabilities, 6, 54-76. 
Maor, D., Currie, J., \& Drewry, R. (2011). The effectiveness of assistive technologies for children with special needs: a review of research-based studies. European Journal of Special Needs Education, 26, 283-298.

Maushak, N. J., Kelley, P., \& Blodgett, T. (2001). Preparing teachers for the inclusive classroom: A preliminary study of attitudes and knowledge of assistive technology. Journal of Technology and Teacher Education, 9, 419-431.

McIntosh, M. (2010). Resistance is futile...Assistive technology and students with learning disabilities. Retrieved from http://www.ldao.ca/wp-content/uploads/AssistiveTechnology-Students-with-LDs.pdf

Mundy, M., Kupczynski, L., \& Kee, R. (2012). Teacher's perceptions of technology use in the schools. SAGE open, 2, 1-8.

Nam, C. S., Bahn, S., \& Lee, R. (2013). Acceptance of assistive technology by special education teachers: A structural equation model approach. International Journal of HumanComputer Interaction, 29, 365-377.

Phillips, B. \& Zhao, H. (1993). Predictors of assistive technology abandonment. Assistive Technology, 5, 36-45.

Roberson, L. (2001). Integration of computers and related technologies into deaf education teacher preparation programs. American Annals of the Deaf, 146, 60-66.

Schlosser, R. W., McGhie-Richmond, D., Blackstein-Adler, S., Mirenda, P., Antonius, K., Janzen, P. (2000). Training a school team to integrate technology meaningfully into the curriculum: Effects on student participation. Journal of Special Education Technology. $15,31-44$

Sider, S. \& Maich, K. (2014). Assistive technology tools: Supporting literacy learning for all learners in the inclusive classroom. What Works? Research Into Practice, 50, 1-4. 
Sharpe, M. E. (2010). Assistive technology attrition: Identifying why teachers abandon assistive technologies (Doctoral dissertation). Retrieved from PsycINFO.

Statistics Canada (2012). Learning disabilities among Canadians aged 15 years and older, 2012. Retrieved from http://www.statcan.gc.ca/pub/89-654-x/89-654-x2014003-eng.pdf

Statistics Solutions. (2013). Data analysis plan: Bivariate (Pearson) Correlation [WWW Document]. Retrieved from http://www.statisticssolutions.com/academicsolutions/member-resources/member-profile/data-analysis-plan-templates/data-analysisplan-bivariate-pearson-correlation/

Watt, D. H. (1980). Computer literacy: What should schools be doing about it. Classroom Computer News, 1, 1-26.

Zapf, S. A., Scherer, M. J., Baxter, M. F., \& Rintala, D. H. (2016). Validating a measure to assess factors that affect assistive technology use by students with disabilities in elementary and secondary education. Disability and Rehabilitation: Assistive Technology, $11,38-49$.

Zeleke, S. (2004). Self-concepts of students with learning disabilities and their normally achieving peers: a review. European Journal of Special Needs Education, 19, 145-170.

Zhou, L., Ajuwon, P. M., Smith, D. W., Griffin-Shirley, N., Parker, A. T., \& Okungu, P. (2012). Assistive technology competencies for teachers of students with visual impairments: A national study. Journal of Visual Impairment \& Blindness, 106, 656-665. 


\section{Tables}

Table 1

Correlations between Years of Teaching, Computer Literacy and Average AT Skills

\begin{tabular}{lcc}
\hline & \multicolumn{2}{c}{ Years of Teaching } \\
\hline & $r$ & $p$ \\
\hline Computer Literacy & .03 & .905 \\
Average AT Skills & .48 & $.023^{*}$ \\
\hline
\end{tabular}

Note. $*=\mathrm{p}<.05 . \mathrm{N}=23$ for all Computer Literacy and $\mathrm{N}=22$ for Average AT Skills analyses. 
Table 2

Qualitative Thematic Analysis and Frequencies

\begin{tabular}{|c|c|c|}
\hline & \multicolumn{2}{|l|}{ Themes } \\
\hline & Example Response & $\begin{array}{l}\text { Number of } \\
\text { Participants Who } \\
\text { Indicated Each } \\
\text { Theme } \\
\text { (n) }\end{array}$ \\
\hline \multicolumn{3}{|l|}{ Technology } \\
\hline \multicolumn{3}{|l|}{ Implementation } \\
\hline access & $\begin{array}{l}\text { "We don't have enough computers or even } \\
\text { working computers for teachers and students" }\end{array}$ & 11 \\
\hline advertisements & "Advertisements." & 1 \\
\hline hardware & $\begin{array}{l}\text { "Kids tripping over projector cords and } \\
\text { unplugging it" }\end{array}$ & 6 \\
\hline internet & "Internet not always working" & 11 \\
\hline software & $\begin{array}{l}\text { "Not being able to install programs that I need } \\
\text { (having to go through the IT department)" }\end{array}$ & 6 \\
\hline speed & "Slow processing speed" & 4 \\
\hline student factors & "Students (not) remembering their passwords" & 2 \\
\hline support & "Waiting for repairs" & 1 \\
\hline training & "Access for all students and easy to use" & 2 \\
\hline \multicolumn{3}{|l|}{ AT Implementation } \\
\hline access & "Quantity of devices" & 2 \\
\hline hardware & "Old tech" & 1 \\
\hline internet & "They do not connect to the internet reliably" & 2 \\
\hline software & "Voice recognition programs are not great" & 4 \\
\hline student factors & $\begin{array}{l}\text { "Teaching students how to use them } \\
\text { independently and having buy-in from students" }\end{array}$ & 7 \\
\hline time & $\begin{array}{l}\text { "Lack of planning/prep time to adequately } \\
\text { support students using AT for my lessons (e.g. } \\
\text { prepping text documents for Google Read/Write, } \\
\text { translating assignments and vocabulary for ELL } \\
\text { students)" }\end{array}$ & 2 \\
\hline training & $\begin{array}{l}\text { "Not enough PD- I often have to teach myself } \\
\text { how to use new assistive technology programs" }\end{array}$ & 6 \\
\hline
\end{tabular}

Note. These are examples of respenses from the open-ended survey items. Examples were selected to reflect the prototypical response. Participants responses may refer to more than one theme. 
Table 3

Factors Discouraging or Encouraging the Use of AT in the Classroom

\begin{tabular}{lcc}
\hline & Most Important Factor \\
\hline & $\begin{array}{c}\text { Percent of } \\
\text { Respondents (\%) }\end{array}$ & $\begin{array}{c}\text { Frequency } \\
(n)\end{array}$ \\
\hline Discouraging Use of AT & & 5 \\
Little support on how and when to use it & 20.8 & 4 \\
Could not figure out how to use it quickly & 16.7 & 3 \\
Difficult to use during instruction & 12.5 & 3 \\
Requires additional time to set up and use & 12.5 & 2 \\
Difficult for student to use & 8.3 & 2 \\
Need additional products/computers to use the technology & 8.3 & 2 \\
No knowledge of how to use the product or what it is for & 8.3 & 1 \\
Additional training & 4.2 & 1 \\
High cost & 4.2 & 11 \\
Encouraging Use of AT & & 5 \\
Assist students individually & 45.8 & 2 \\
Increases learning & 20.8 & 2 \\
Ease of use for students & 8.3 & 1 \\
Easy to use; user friendly & 8.3 & 1 \\
Know what product is for and how to use it & 4.2 & 1 \\
Little extra training is needed & 4.2 & \\
Overall cost is worth the benefits or gains it gives the & 4.2 & \\
students & &
\end{tabular}

Note. Participants were asked to rank the most important factor encouraging and discouraging the implementation of AT into their classroom. Percentages refer to the percent total participants who selected each option as the most important factor. 1 missing value from each scale. 
Table 4

Internal Consistency Analysis

\begin{tabular}{llcc}
\hline & & \multicolumn{2}{c}{ Reliability Statistics } \\
\hline Scale & Author(s) & Cronbach's Alpha & Items $(N)$ \\
\hline Student Demographics & N/A & .83 & 11 \\
Computer Literacy & N/A & .92 & 9 \\
AT Knowledge and Resources & Lee \& Vega (2005) & .94 & 17 \\
AT Skills & N/A & .90 & 21 \\
Perceived Usefulness & Nam et al. (2013) & .85 & 8 \\
\hline
\end{tabular}

Note. Internal consistency (Cronbach's Alpha) based on the current study data. 


\section{Figures}

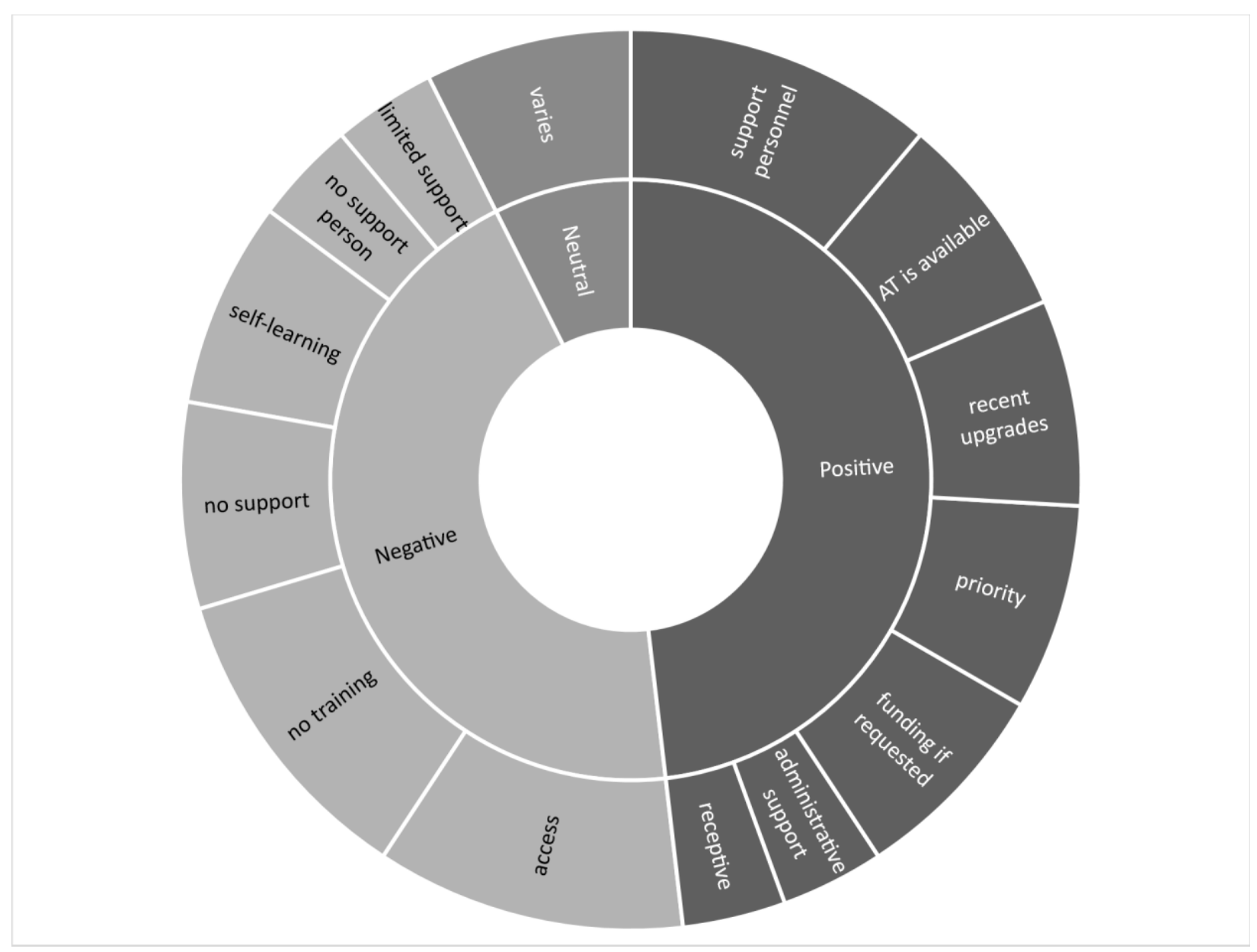

Figure 1. Orientations of perception of support and themes related to AT orientation.

Note. A thematic analysis was used to identify themes in participants' responses regarding AT, then each theme was defined as Positive, Negative, or Neutral. The size of the blocks represents the frequency of each response. 


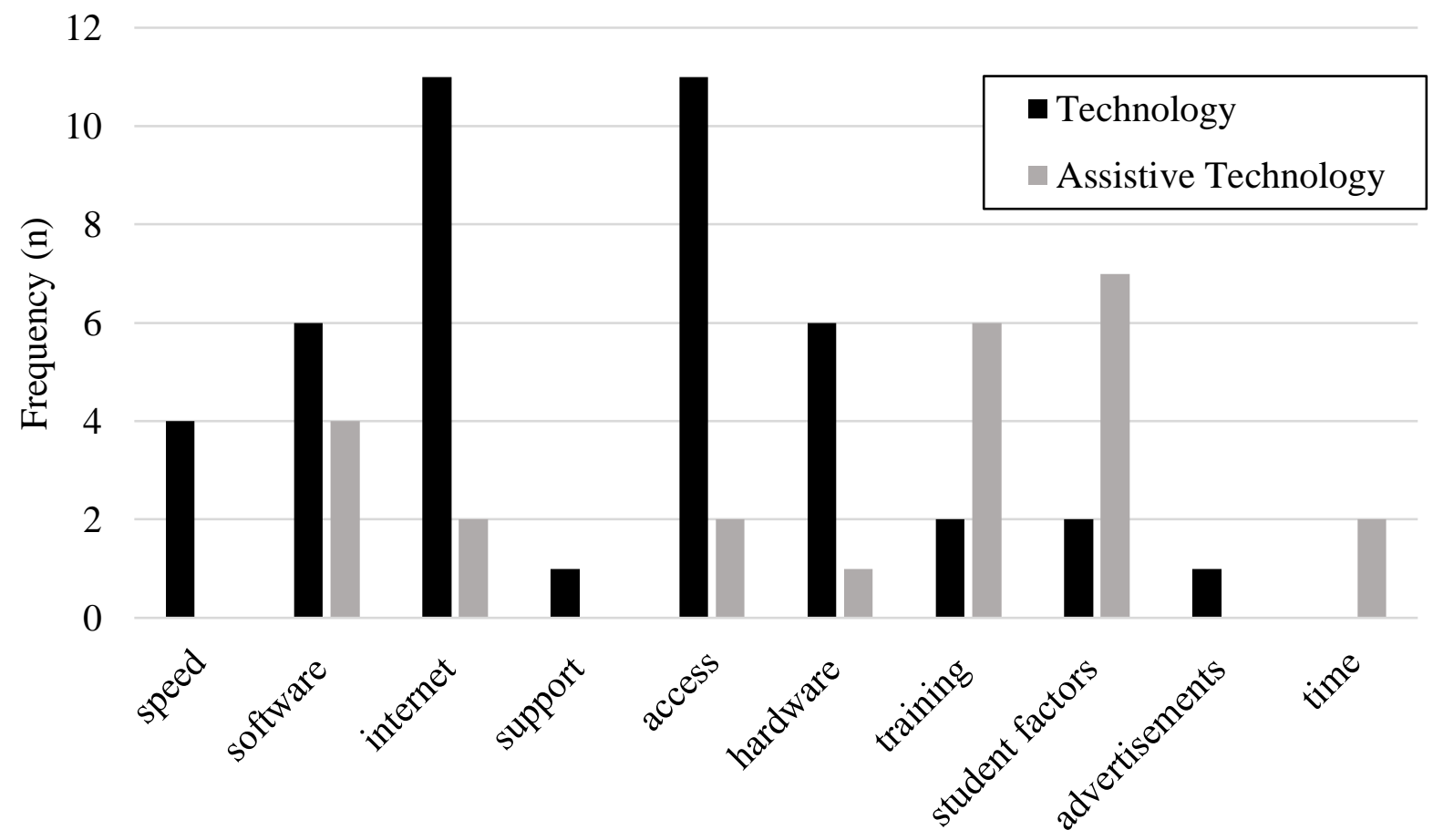

Qualitative Theme

Figure 2. Frequency of themes related to factors that hinder the use of technology and AT.

Note. A thematic analysis was used to identify themes in participants' responses. Participants could have identified more than one theme in their response. 


\section{Appendices}

\section{Appendix A: Survey}

1. What is your gender? Mark only one oval.

- Male

- Female

- Prefer not to say

- Other:

2. What grade(s) do you teach? Select all that apply.
- 6
- 7
- 8
- 9
- 10
- Other:

3. How many years have you been teaching?

4. What subject(s) do you teach? Check all that apply.
- English
- Science
- Math
- French
- Special Education
- Music
- Art
- Drama
- Technology
- Physical Education
- Other:

5. What country do you live in? Mark only one oval.

- Canada

- United States of America

- Other:

6. In what school board do you teach? Mark only one oval.

- Algoma District School Board

- Algonquin and Lakeshore Catholic District School Board

- Avon Maitland District School Board 
- Bloorview School Authority

- Bluewater District School Board

- Brant Haldimand Norfolk Catholic District School Board

- Bruce- Grey Catholic District School Board

- Campbell Children's School Authority

- Catholic District School Board of Eastern Ontario

- Conseil des écoles catholiques du Centre-Est

- Conseil des écoles publiques de l'Est de l'Ontario

- Conseil scolaire catholique Franco-Nord

- Conseil scolaire catholique Providence

- Conseil scolaire de district catholique Centre- Sud

- Conseil scolaire de district catholique de l'Est ontarien

- Conseil scolaire de district catholique des Aurores boréales

- Conseil scolaire de district catholique des Grandes Rivières

- Conseil scolaire de district catholique du Nouvel- Ontario

- Conseil scolaire de district du Grand Nord de l'Ontario

- Conseil scolaire de district du Nord-Est de l'Ontario

- Conseil scolaire Viamonde

- District School Board of Niagara

- District School Board Ontario North East

- Dufferin-Peel Catholic District School Board

- Durham Catholic District School Board

- Durham District School Board

- Grand Erie District School Board

- Greater Essex County District School Board

- Halton Catholic District School Board

- Halton District School Board

- Hamilton- Wentworth Catholic District School Board

- Hamilton- Wentworth District School Board

- Hastings \& Prince Edward District School Board

- Huron Perth Catholic District School Board

- Huron- Superior Catholic District School Board

- James Bay Lowlands Secondary School Board

- John McGivney Children's Centre School Authority

- Kawartha Pine Ridge District School Board

- Keewatin -Patricia District School Board

- Kenora Catholic District School Board

- Lakehead District School Board

- Lambton Kent District School Board

- Limestone District School Board

- London District Catholic School Board

- Moose Factory Island District School Area Board

- Moosonee District School Area Board

- Near North District School Board

- Niagara Catholic District School Board

- Niagara Peninsula Children's Centre School Authority

- Nipissing-Parry Sound Catholic District School Board 
- Northeastern Catholic District School Board

- Northwest Catholic District School Board

- Ottawa Catholic School Board

- Ottawa Children's Treatment Centre School Authority

- Ottawa -Carleton District School Board

- Peel District School Board

- Penetanguishene Protestant Separate School Board

- Peterborough Victoria Northumberland and Clarington Catholic District School Board

- Provincial Schools Branch (Ontario Ministry of Education)

- Rainbow District School Board

- Rainy River District School Board

- Renfrew County Catholic District School Board

- Renfrew County District School Board

- Simcoe County District School Board

- Simcoe Muskoka Catholic District School Board

- St. Clair Catholic District School Board

- Sudbury Catholic District School Board

- Superior North Catholic District School Board

- Superior -Greenstone District School Board

- Thames Valley District School Board

- The KidsAbility School Authority

- Thunder Bay Catholic District School Board

- Toronto Catholic District School Board

- Toronto District School Board

- Trillium Lakelands District School Board

- Upper Canada District School Board

- Upper Grand District School Board

- Waterloo Catholic District School Board

- Waterloo Region District School Board

- Wellington Catholic District School Board

- Windsor -Essex Catholic District School Board

- York Catholic District School Board

- York Region District School Board

- Other

\section{Student Demographics}

7. Do you have students with IEPs?

An Individual Education Plan, or IEP, is a legal document developed by the school, which spells out a child's learning needs, the services the school will provide and how progress will be measured. Mark only one oval.

- Yes

- No 
- Don't Know

8. What types of special needs students have you worked with? Mark only one oval per row.

\begin{tabular}{|c|c|c|c|c|c|}
\hline & $\begin{array}{l}\text { Not at } \\
\text { all }\end{array}$ & Knowledge of & $\begin{array}{l}\text { Worked } \\
\text { with some }\end{array}$ & $\begin{array}{l}\text { Worked } \\
\text { with many }\end{array}$ & Expert \\
\hline LD & & & & & \\
\hline ELL & & & & & \\
\hline DD & & & & & \\
\hline MID & & & & & \\
\hline ASD & & & & & \\
\hline Gifted & & & & & \\
\hline Behavioural & & & & & \\
\hline ADHD & & & & & \\
\hline Visual Impairment & & & & & \\
\hline Motor Impairment & & & & & \\
\hline Deaf/Hard of Hearing & & & & & \\
\hline
\end{tabular}

9. How many students do you have with IEPs?

10. Do you have any students with SEA Claims? 
A Special Equipment Amount, or SEA Claim, is funding that is used to assist school boards with the costs of equipment essential to support students with special needs. Mark only one oval.

- Yes

- No

- Don't Know

11. How many students do you have with SEA Claims?

12. Did your teacher education program cover Assistive Technology (AT)?

Assistive Technology (AT) has been identified as any technology that can assist or improve the functional capabilities of individuals with a disability (Wissick, \& Gardner, 2008). Mark only one oval.

- Yes

- No

- Don't Know

13. Have you ever taken a Special Education Advanced Qualification (AQ) course? Mark only one oval.

- Yes

- No

14. Did this AQ cover Assistive Technology (AT)? Mark only one oval.

- Yes

- No

- Don't Know

\section{Technology}

15. How many years have you been using computers? Put 0 if you have never used a computer.

16. What type of technology do you use? Select all that apply.

- Windows

- Mac

- Linux

- iPad

- Android tablet

- Smartphone

- iPod

- None of the above 
- Other:

17. What devices do you own? Select all that apply.

- Windows Desktop

- Windows Laptop

- Windows Tablet

- iMac

- Mac Laptop

- iPad

- Chromebook

- Netbook

- Android Tablet

- Smartphone

- iPod

- None of the above

- Other:

18. What operating systems are you familiar with? Select all that apply.

- Windows 7

- Windows 8

- Windows 10

- MAC OS

- iOS

- Android

- Linux

19. Who taught you how to use a computer in the first place? Mark only one oval.

- Trainer / Teacher

- Colleagues

- Family

- Friends

- Books

- Videos

- Yourself

- Other:

Rate each of the following from 1 (Poor) to 5 (Excellent).

20. How would you rate your computer literacy?

21. How would you rate your internet literacy?

22. How would you rate your current typing skills?

23. How would you rate your basic computer skills? Mark only one oval per row. 


\begin{tabular}{|l|l|l|l|l|}
\hline & None & Basic & Intermediate & Advanced \\
\hline Word Processing applications & & & & \\
\hline Spreadsheet applications & & & & \\
\hline Database applications & & & & \\
\hline Presentation applications & & & & \\
\hline Multimedia applications & & & & \\
\hline Web design applications & & & & \\
\hline Web search engines & & & & \\
\hline Email & & & & \\
\hline Graphics applications & & & & \\
\hline
\end{tabular}

24. Please indicate how frequently you use each of the following. Mark only one oval per row.

\begin{tabular}{|l|l|l|l|l|l|l|l|}
\hline $\begin{array}{l}\text { Never } \\
\text { Used }\end{array}$ & Rarely & $\begin{array}{l}1-2 \\
\text { times }\end{array}$ & $\begin{array}{l}1-2 \\
\text { times }\end{array}$ & $\begin{array}{l}3-4 \\
\text { times }\end{array}$ & $\begin{array}{l}\text { Almost } \\
\text { everyday }\end{array}$ & $\begin{array}{l}\text { Many } \\
\text { times } \\
\text { a day }\end{array}$ \\
\hline
\end{tabular}




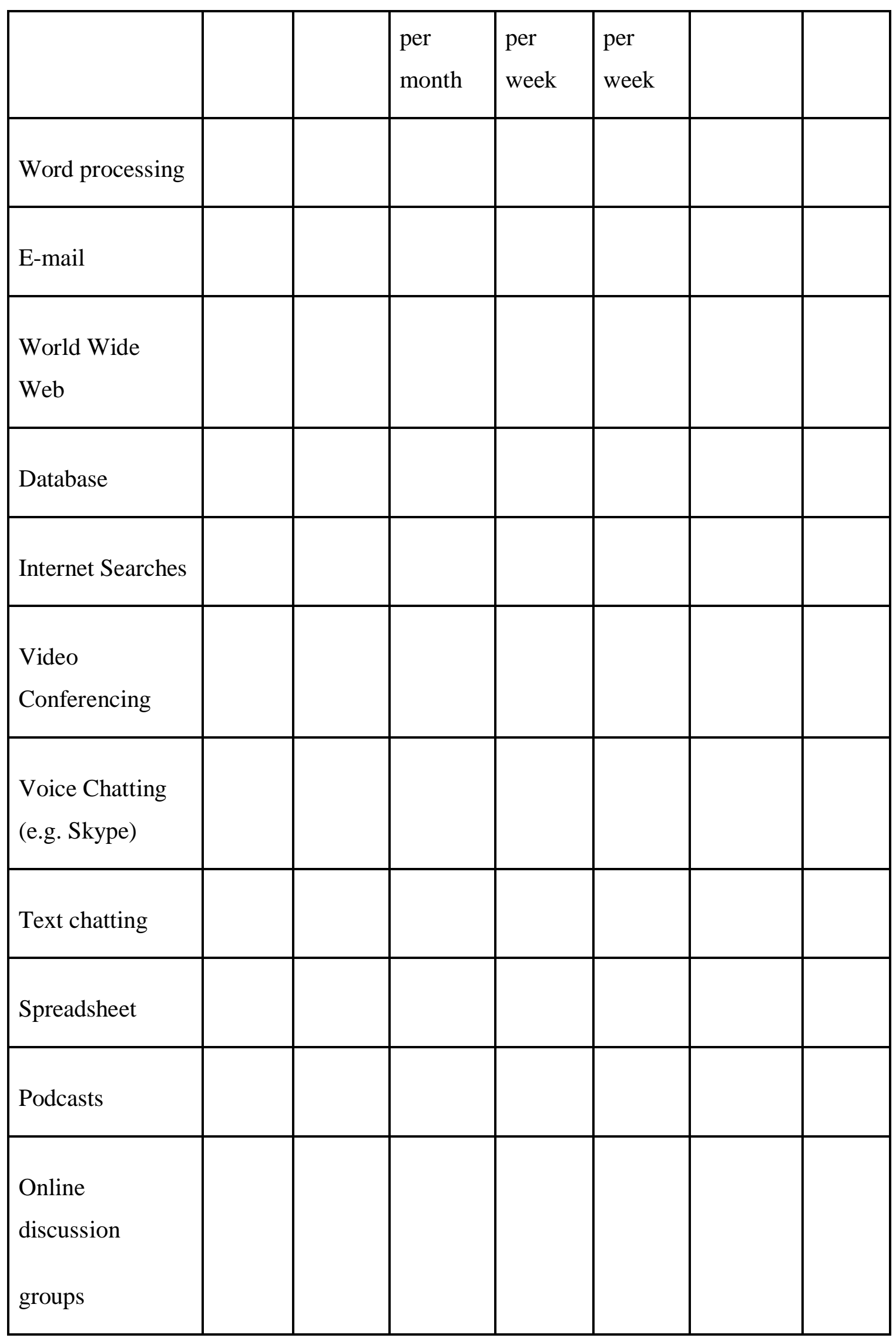




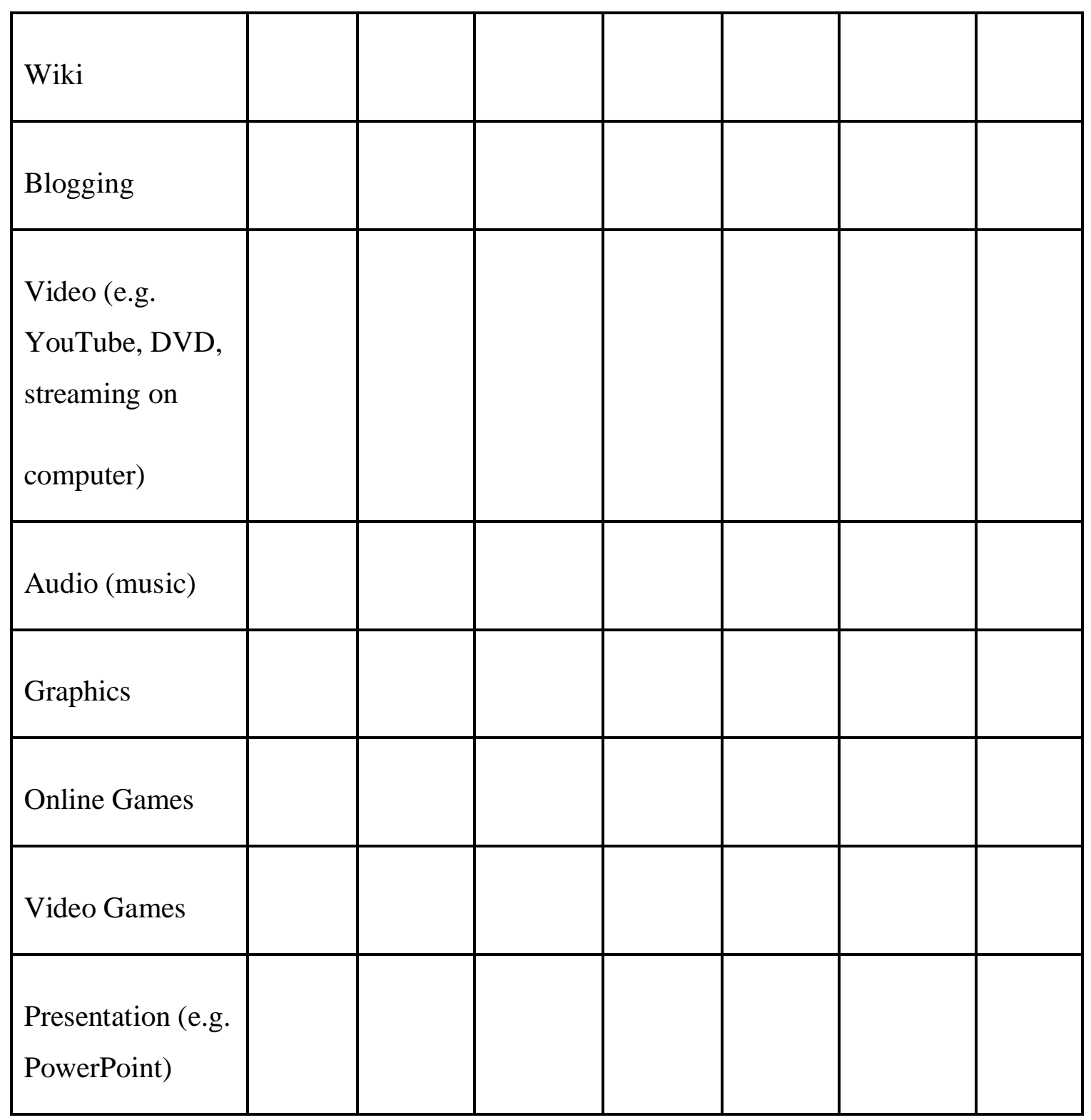

25. How many minutes per day do you spend using technology? For example, if you spend one hour using technology per day, you would write 60.

26. What common problems do you have with using technology at school?

27. What common problems do you have with using AT programs at school?

28. How many computers are in your classroom? Mark only one oval.
- 1
- 2
- 3
- 4 
- 5

- Other:

\section{Perceptions}

29. How would you rate your assistive technology skills? Mark only one oval per row.

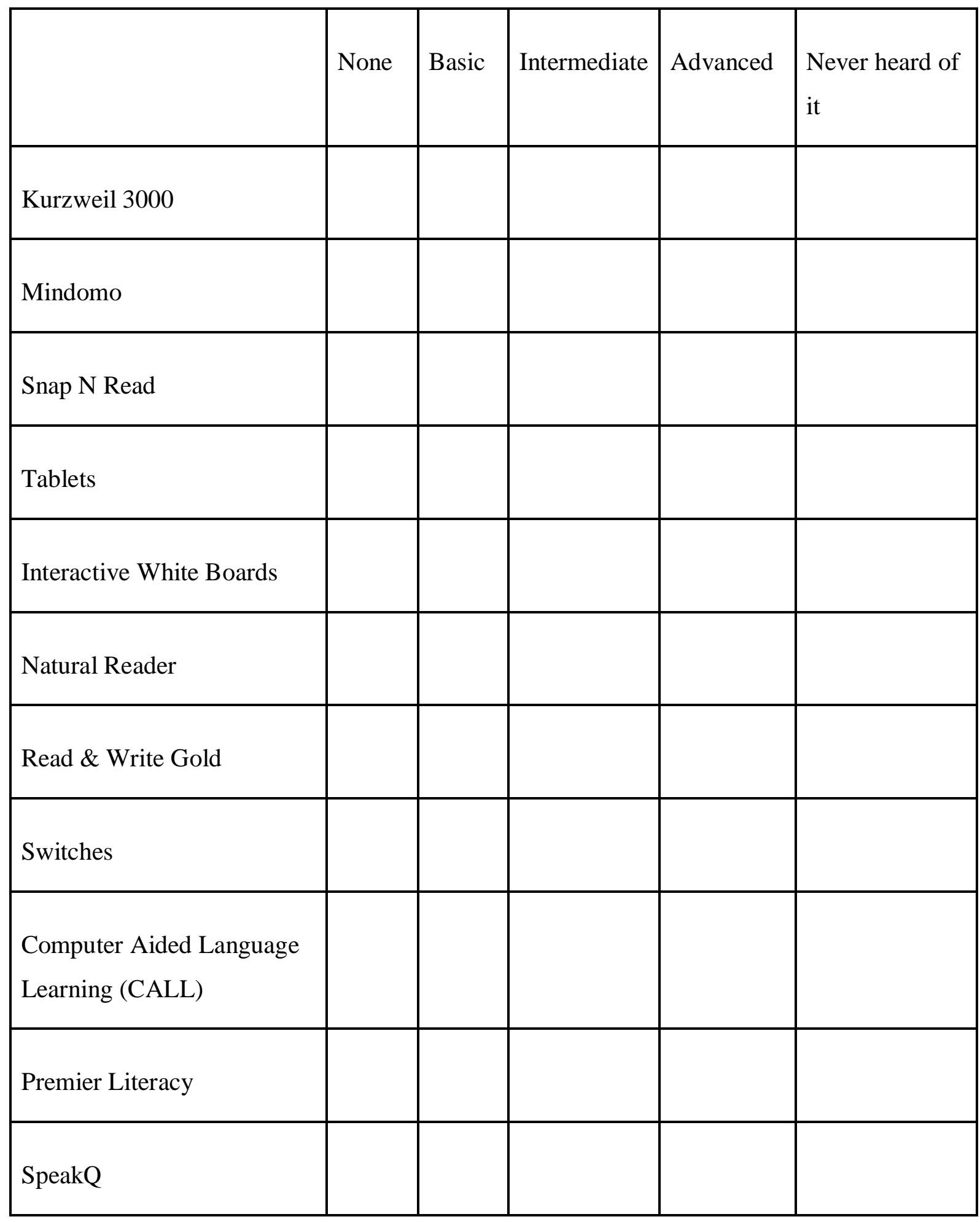




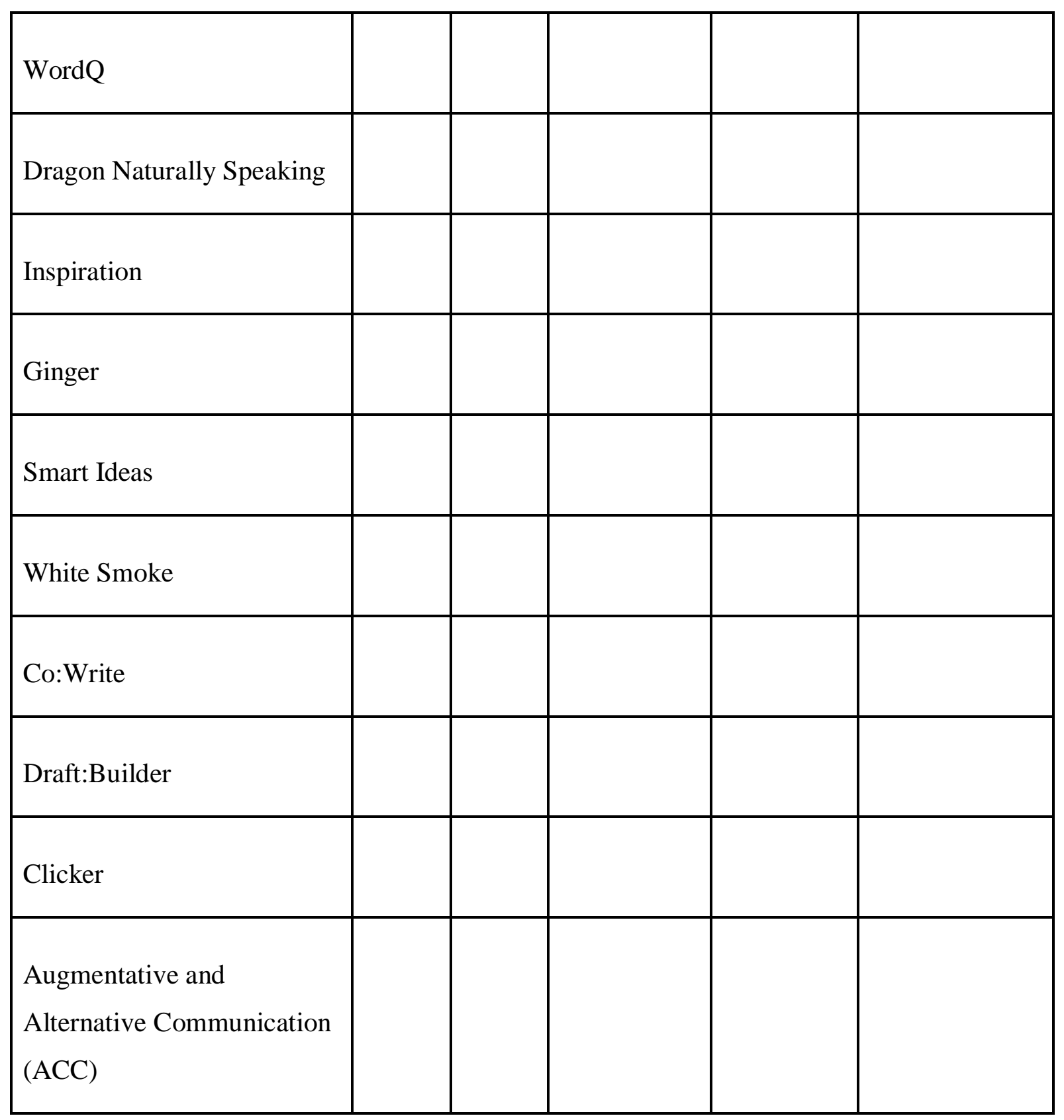

30. How supportive is technology implementation in your school? Mark only one oval.

Rate from 1(Very Unsupportive) to 5 (Very Supportive)

\section{Explain.}

32. Have you attended any talks or conferences about Assistive Technology? Mark only one oval.

- Yes

- No 
33. If so, what ones? Select all that apply.

- I have not attended any conferences or talks

- Association for Special Education Technology (ASET) Conference

- Assistive Technology Industry Association (ATIA) Conference

- The Assistive Technology Conference of New England

- Power-Up Conference and Expo

- Rehabilitation Engineering and Assistive Technology of North America (RESNA)

- Accessing Higher Ground (AHG)

- Other:

34. How useful did you find these experiences? You may skip this question if you did not attend any conferences. Mark only one oval per row.

Rate each of the conferences in the previous item:

- Not at all useful

- Not very useful

- Neutral

- Somewhat useful

- Very useful

35. What technology is available to students in your school? Select all that apply.

- iPads

- PC Computer Labs

- Mac Computer Labs

- Chromebooks

- Netbooks

- In- Class PCs

- Laptops

- SmartBoard

- Other:

Perceptions (2) (Lee \& Vega, 2005)

Rate each of the following from 1 (Strongly Disagree) to 5 (Strongly Agree).

36. I feel comfortable using AT with my students.

37. AT Information is easy to obtain in my school district.

38. I have time to increase my technology--related knowledge and skills. 
39. AT assistance is readily available at my school.

40. AT is an important part of the daily routine for all of my students.

41. It is easy for me to adapt AT to meet my students' needs.

42. I am knowledgeable of AT for students with sensory disorders (e.g., vision or hearing impairment).

43. I am able to use technology to compensate for my students' learning/performance barriers and challenges.

44. I can identify and use AT to provide access to educational materials otherwise inaccessible to some individuals.

45. I know how, when, and where to refer a student regarding AT.

46. I can arrange and manage the classroom environment to facilitate AT use.

47. I am able to identify and operate software that meets my students' educational objectives.

48. I am knowledgeable of augmentative communication methods and devices.

49. I am knowledgeable of reading and math software for my students.

50. I have knowledge of AT assessment.

51. My administrators support AT use for my students.

52. I am knowledgeable of AT for those who have physical disabilities (i.e., fine motor or gross motor problems).

Usefulness (Chang, Sangwoo, \& Lee, 2013)

Rate each of the following from 1 (Strongly Disagree) to 5 (Strongly Agree).

53. The performance of my student is improved by using the technology. 
54. The productivity of my student is improved by using the technology.

55. Using the technology enhances my job effectiveness.

56. I believe I would find it easy to get the technology to do what I wanted it to do.

57. I believe it would be easy for me to become skilled at using the technology.

58. I think the technology would be easy to use.

59. I have the resources I need to use the technology in an effective way.

60. There is a specific person or persons I can go to for assistance to help me with any difficulties I might have when using the technology.

(Flanagan et al., 2013)

61. Please indicate which of the factors below DISCOURAGE technology use in your classroom by students with special education needs. Select all that apply.

- High cost

- Additional training

- Requires additional time to set up and use

- Difficult to use during instruction

- Need additional products/computers to use the tech

- Little support on how and when to use it

- Difficult for student to use

- School computers do not support AT

- Could not figure out how to use it quickly

- No knowledge of how to use the product or what it is for

- Difficult for you the teacher to use it

- Students do not learn anything differently using the AT

62. Please indicate which of the factors below ENCOURAGE technology use in your classroom by students with special education needs. Select all that apply.

- Increases learning

- Assists students individually

- Can use it with more than one student

- Can use it with several students at one time

- Ease of use for students

- Is easy how to figure out how to use; user friendly

- Ease of integration into the classroom and instruction

- Overall cost is worth the benefits or gains it gives the students 
- Can quickly set up or customize for student

- Know what product is for and how to use it

- Little extra training is needed

- Low to moderate cost

63. Any other factors that help or hinder use of the assistive technology in your classroom?

64. What types of problems would lead you to suggest AT for a student in your classroom related to literacy skills? 